\title{
Assessing Determinants of Job Satisfaction among Certified Nursing Assistants in Acute Care
}

\author{
Ronnie Ursin ${ }^{1^{*}}$ \\ ${ }^{1}$ Chief Nursing Officer, Northern Louisiana Medical Center
}

Received: March 24, 2017; Accepted: : May 4, 2017; Published: May 7, 2017

*Corresponding author: Ronnie Ursin, Chief Nursing Officer, Northern Louisiana Medical Center, Louisiana 71270; Tel: [504] 782-0136; Fax: [318]2748104. E-mail:- ronnieursin@gmail.com

\begin{abstract}
Background: A Certified Nursing Assistant (CNA) provides important components of basic patient care in Acute Care (AC) settings. CNAs provide up to $90 \%$ of the care that a patient receives. Sustainability of the CNA workforce is imperative for the health care industry. The aim of this study was to assess the determinants of job satisfaction among CNAs in acute care settings using the determinants of job satisfaction identified among CNAs employed in long-term care.
\end{abstract}

Methods: This descriptive, correlation study used a sample of 35 CNAs employed in acute care who voluntarily completed a job satisfaction questionnaire. Participants were employed at two nonprofit AC hospitals: a 286-bed community and a 319-bed regional in the southern United States of America.

Results: Job satisfaction was rated at 8.2 on a scale of 10 . Assessment of determinants of job satisfaction showed work content and quality of care were rated on the higher end of the scale $(>9.0)$. Training, education, relationship with nursing colleagues, work demands, workload, and pay were rated the lowest in satisfaction $(<7.6)$.CNAs with longevity tend to be more satisfied with their coworkers.

Conclusion: Journal articles were searched in the nursing and business literature finding studies performed across the world. However, most job satisfaction studies about CNAs have been conducted in long-term care facilities with a limited number specifically addressing job satisfaction of CNAs in acute care. CNAs are valuable assets to providing basic care to patients. CNA job satisfaction may improve with structured approaches to address training, education, workload, and pay. Additional research is needed to identify strategies to enhance job satisfaction and provide ongoing assessment on the determinants of job satisfaction of CNAs employed in $\mathrm{AC}$.

Keywords: Certified Nursing Assistant; Nurse Aids; CNA; Unlicensed Assistive Personnel; CNA, Long-Term; LTC; Acute Care; AC

\section{Introduction}

\section{Job Satisfaction}

Job satisfaction is a complex phenomenon with multiple causative [26]. Maintaining employee satisfaction is vital and must be considered essential for healthcare enterprise sustainability. Sustainability of any enterprise is likely aligned with satisfied employees having the desire to be more productive and creative [9]. Andrica suggested employees want to feel successful and respected [10]. Employees may overlook their negative perceptions of an enterprise and persevere in time of crisis. Most importantly for healthcare enterprises, studies have shown a direct correlation between staff and patient satisfaction [11].

Job satisfaction has been studied from many different perspectives [12,13]. Researchers across a number of disciplines have examined job satisfaction in relationship to pregnancy, education, military regulations, organizational ethics, participative management, teamwork, cultural values, and gender segregation. Brown, et al. suggested women's job satisfaction was significantly higher prior to pregnancies and found a positive correlation between satisfaction and maternity leave [13]. Harrington, et al. found Air Force family advocacy program workers were more likely to leave employment if they experienced low levels of intrinsic job satisfaction or felt dissatisfied with salary and promotional opportunities [20].

Organizational ethics and cultural values supported by leadership were found to have positive implications for job satisfaction [14,15]. Eisenberger, et al. found organizational leaders can favorably influence outcomes while actively engaging in and rewarding ethical behavior [16]. Findings suggested employees who are increasingly satisfied are absent less, less likely to leave, and more likely to display quality organizational behaviors. Bender, et al. supported the perception that women have lower expectations in the workplace and are easily satisfied with work experience [12]. Findings also suggested women are more satisfied in careers dominated by women, but did not show support for men being more satisfied in careers dominated by men. Although job satisfaction research reaches across all disciplines and is extensive in healthcare, researchers have failed to fully investigate job satisfaction among Certified Nursing Assistants (CNAs) in healthcare with specific emphasis in AC settings.

\section{Theoretical Framework and Conceptual Model}

Certain needs are basic to all people and require satisfaction accordingly [17]. Maslow's hierarchy of needs theory posits that a basic, low-level need must be met before higher level needs can be pursued. Maslow's theory states when one need is 
mostly satisfied it no longer motivates and the next higher need takes its place; as soon as one need is met, satisfaction of the next higher need is sought.

According to Frederick Herzberg's hygiene and motivation theory, people are influenced by two factors: hygiene and motivation [18]. Hygiene factors are entities that involve the work and organizational environment including the enterprise structure, policies, supervision, processes, working conditions, interpersonal relations, compensation, and job security. Motivation factors include perceptions within the individual including achievement, recognition, growth and advancement. Hygiene factors do not lead to higher levels of motivation, but without hygiene factors dissatisfaction tends to exist. Motivation factors result from internal instincts in employees, yielding motivation rather than movement, and are strong determinants of job satisfaction. To positively impact employee job satisfaction the employee must perceive that both hygiene and motivation factors are positive.

\section{Certified Nursing Assistants and Job Satisfaction}

In AC settings, CNAs share responsibility for personal care with a Registered Nurse (RN). CNAs are critical team members providing more than $70 \%$ of direct patient care $[2,21]$. CNAs may be responsible for services such as bathing, ambulating, transporting, and feeding patients [1]. Patients receive social and emotional support from CNAs who also provide vital information about the patient's condition to RNs [3].

Turnover among CNAs in LTC reached critical proportions in 1999 [4]. Parsons, et al. found 30\% of the CNA workforce leaves LTC positions within 4.6 years of employment due to dissatisfying factors [5]. Although research that quantifies CNA turnover in AC was not found, anecdotal information suggests there may be similar turnover of CNA in AC. Several studies support determinants affecting CNA job satisfaction in LTC include communication, advancement, rewards, recognition and pay structure but the research has not been tested in the AC setting [2,5-8]. Similar studies included determinants impacting CNA job satisfaction such as staffing, work hours, respect, leadership, and engagement [21-25]. Lerner, et al. found years of experience and self-esteem had a positive impact on CNA satisfaction [26]. Another study found determinants such as benefits, training, organizational culture, and staffing may have an effect on job satisfaction and retention but not on compensation [27]. Given the important role of a CNA, healthcare leaders cannot allow low job satisfaction to be a deterrent to successfully retaining CNAs.

The aim of this study was to assess the determinants of job satisfaction among CNAs in acute care using the determinants of job satisfaction identified by Castle among CNAs employed in LTC [2].

\section{Methods}

The descriptive, correlation study was conducted using a convenience sample of CNAs employed in AC. Participants were employed at two non-profit AC hospitals: a 286-bed community and a 319-bed regional in two southern states. A total of 70 CNA were employed at the research sites, but 20 were excluded based on the inclusion criterion.

\section{Instruments}

The study questionnaires included a demographicprofile developed by the researcher and the Nursing Home Nurse Aide - Job Satisfaction Questionnaire (NHNA-JSQ).The NHNA-JSQ is a nursing assistant job satisfaction questionnaire with established validity and reliability containing 21 questions; 19 questions are designed to understand determinants of job satisfaction and 2 are designed to rate CNA overall job satisfaction and whether the CNA would recommend their respective employer. Each item is scored using a visual analogue format with an interval scale from 1(lowest) to 10 (highest). There are seven subscales including coworkers, work demands, work content, workload, training, rewards, and quality of care.

\section{Research Participant Protection}

The approval to conduct the study was granted by the Institutional Review Board (IRB) at the 319-bed hospital and in the absence of an IRB, the administration of the 286-bed health system, and the IRB of Case Western Reserve University.

\section{Results}

\section{Response Rate}

Although, together, 70 CNAs were employed at the two study sites, 20 of those 70 were under the direct leadership of the researcher and were excluded from eligibility for participation, leaving 50 potential participants. A total of 40 of those 50 CNA volunteered to participate. A total of 36 participants voluntarily completed the questionnaires resulting in a $90 \%$ response rate. Four were returned blank and one participant indicated that a performance evaluation was completed one month prior to the study, an exclusion criterion.

\section{Demographics}

Participants ranged in age from 25 to 63 years with a mean age of 39.8 years. The SD for age was 12 years. Of the participants, $20(57.1 \%)$ were 35 years of age or older. The most common age among the participants was 28. All, but one, participants (97.1\%) were female and one was male. A total of 32 $(91.4 \%)$ of the participants identified themselves as black from among the seven racial categories available while three (8.6\%) identified themselves as white. Most (80\%) of the participants were either married or single. Just four $(11.4 \%)$ were divorced and two $(5.7 \%)$ were widowed. Only one participant (2.9\%) selfidentified as partnered.

In all, 32 (91.4\%) had graduated from high school. Only $3(8.6 \%)$ had less than a high school diploma. Over half of the participants $(n=18,51.4 \%)$ had some college education or were college graduates. The distribution of education is presented in (Table 1).

Fluid overload is one clinical factor that not only affects the mother, but the newborn infant as well. A newborn may appear bloated when the mother receives excess intravenous 


\begin{tabular}{|c|c|c|}
\hline \multicolumn{3}{|c|}{ Table 1: Demographic Profile of Sample - Education } \\
\hline Level of Education [n = 35] & $\mathbf{n}$ & [\%] \\
\hline Some high school & 3 & 8.6 \\
\hline High school graduate & 14 & 40.0 \\
\hline Some college & 12 & 34.3 \\
\hline College graduate & 6 & 17.1 \\
\hline
\end{tabular}

Thirty-four of thirty-five participants worked a full-time schedule. Data collection was timed to accommodate potential participants working all three shifts but most $(62.9 \%)$ of the participants worked the day shift. Only six (17.1\%) worked a second job. The distribution of employment status and shift is presented in (Table 2).

Table 2: Demographic Profile of Sample - Employment Status and Shift

\begin{tabular}{|l|l|l|}
\hline Employment Status [n = 35] & $\mathbf{n}$ & [\%] \\
\hline Full-time & 34 & 97.1 \\
\hline Part-time & 1 & 2.9 \\
\hline Work Shift [n= 35] & $\mathbf{n}$ & {$[\%]$} \\
\hline Day & 22 & 62.9 \\
\hline Evening & 4 & 11.4 \\
\hline Night & 9 & 25.7 \\
\hline 2nd Employment [n=6] & $\mathbf{n}$ & {$[\%]$} \\
\hline Full-time & 1 & 16.7 \\
\hline Part-time & 3 & 50.0 \\
\hline On-call/PRN & 2 & 33.3 \\
\hline
\end{tabular}

Participants were asked about the number of years they had worked as a CNA and how many years they had worked in the current position. Experience ranged from 2 to 40 years. The mean for years worked was 12.39 (SD 9.13).
The majority (60\%) had eleven or fewer years' experience. Years worked in the current position ranged from 0 to 40 but the mean for years in current position was only 8.29 (SD 7.31). This suggests that there was turnover among CNA who participated in the study. The distribution of years of employment is presented in (Table 3).

\begin{tabular}{|c|c|c|}
\hline \multicolumn{3}{|c|}{ Table 3: Demographic Profile of Sample - Years as CAN } \\
\hline Years Worked as CNA[n = 35] & M & SD \\
\hline & 12.39 & 9.13 \\
\hline Years in Current Position [n = 35] & M & SD \\
\hline & & \\
\hline
\end{tabular}

\section{Research Questions}

What was the level of job satisfaction among CNAs employed in AC as measured by the NHNA-JSQ?

The NHNA-JSQ included seven subscales: (a) work content; (b) quality of care; (c) training; (d) coworkers; (e) work demands; (f) workload; and (g) rewards. Each of the 19 questions was rated from 1 to 10 with 1 being low and 10 being high. In addition, two questions sought a global perception of CNA job satisfaction.

CNA rated work content satisfaction at 9.1. Other subscales receiving a relatively high score were quality of care (9.2), and training (8.7). However, participants rated their chances for more training low (7.5). Participants rated their coworkers lower (7.4) than training. Low ratings were also given to work demands (7.0) and workload (7.6). Participants gave the lowest score to rewards (5.6) that included pay and chances for advancement. However, overall satisfaction with the job was 8.1 and whether or not they would recommend their employer to a friend scored 8.3. Overall, the global questions were rated 8.2 (Table 4).

Table 4: Job Satisfaction Subscale Means with Item Mean and Standard Deviation [n=35]

\begin{tabular}{|c|c|c|c|c|}
\hline Subscale & Item & Overall Subscale Mean & Item Mean & SD \\
\hline \multirow[t]{4}{*}{ Work Content } & & 9.1 & & \\
\hline & Rate how much you enjoy working with patients & & 9.7 & .7 \\
\hline & Rate how your role influences the lives of patients & & 9.0 & 1.3 \\
\hline & Rate your closeness to patients and families & & 8.7 & 1.3 \\
\hline \multirow[t]{3}{*}{ Quality of Care } & & 9.2 & & \\
\hline & Rate the care given to the patients & & 9.3 & 1.2 \\
\hline & Rate the effect you have on patients' lives & & 9.2 & 1.2 \\
\hline \multirow[t]{4}{*}{ Training } & & 8.7 & & \\
\hline & Rate the training you have had to do your job & & 8.9 & 1.5 \\
\hline & Rate whether your skills are adequate for the job & & 9.5 & 1.0 \\
\hline & Rate the chances you have for more training & & 7.5 & 2.5 \\
\hline \multirow[t]{4}{*}{ Coworkers } & & 7.4 & & \\
\hline & Rate the people you work with & & 7.6 & 2.0 \\
\hline & Rate whether you feel part of a team effort & & 7.4 & 2.2 \\
\hline & Rate the cooperation among staff & & 7.3 & 2.1 \\
\hline
\end{tabular}




\begin{tabular}{|c|c|c|c|c|}
\hline Work Demands & & 7.0 & & \\
\hline & Rate the amount of support you get when doing your job & & 7.3 & 2.4 \\
\hline & Rate the chances you have to talk about your concerns & & 6.6 & 2.6 \\
\hline & Rate the demands patients and their families place on you & & 7.2 & 2.6 \\
\hline \multirow[t]{4}{*}{ Workload } & & 7.6 & & \\
\hline & Rate your workload & & 6.8 & 2.5 \\
\hline & Rate your work schedule & & 7.7 & 2.5 \\
\hline & Rate the amount of time you have to do your job & & 8.2 & 2.2 \\
\hline \multirow[t]{3}{*}{ Rewards } & & 5.6 & & \\
\hline & Rate how fairly you are paid & & 5.5 & 2.4 \\
\hline & Rate your chances for advancement & & 5.6 & 2.7 \\
\hline \multirow[t]{3}{*}{ Global Rating } & & 8.2 & & \\
\hline & Generally speaking, rate how satisfied you are with your job & & 8.1 & 2.3 \\
\hline & Would you recommend working at this facility to a friend? & & 8.3 & 2.2 \\
\hline
\end{tabular}

How did the demographic and background characteristics of the study participants impact their level of job satisfaction?

Pearson correlation coefficient and t test statistics were used. Pearson correlation coefficients were calculated for the relationships between participants' age, years as a CNA, years in current position, and each variable of the NHNA-JSQ. There were no statistically significant findings associated with participants' age or years in their current position and job satisfaction variables. A moderately positive correlation $(\mathrm{r}=.374, \mathrm{p}<0.05)$ was found between years worked as a CNA and participants' ratings of their coworkers. Participants with a greater number of years worked as a CNA tended to be highly satisfied with the people with whom they worked. The correlation analyses are presented in (Table 5).

Table 5: Relationship between Years Worked as a CNA and Job Satisfaction Variables [ $\mathrm{n}=35]$

\begin{tabular}{|c|c|c|c|c|}
\hline Demographic & $\begin{array}{c}\text { Statistical } \\
\text { Test }\end{array}$ & $\begin{array}{c}\text { People } \\
\text { You } \\
\text { Work With }\end{array}$ & $\begin{array}{c}\text { Cooperation } \\
\text { Among Staff }\end{array}$ & $\begin{array}{c}\text { Amount of } \\
\text { Support }\end{array}$ \\
\hline $\begin{array}{c}\text { Years Worked as } \\
\text { a CNA }\end{array}$ & $\begin{array}{c}\text { Pearson } \\
\text { Correlation }\end{array}$ & $.374^{*}$ & $.355^{*}$ & $.338^{*}$ \\
\hline * & & & \\
\hline
\end{tabular}

* Statistical significance $\mathrm{p} \leq 0.05$

A $t$ test was performed to examine the relationship between participants' level of education and each item on the NHNA-JSQ.

Table 6: Level of Education and Job Satisfiers
Level of education was presented as the following: (a) no high school; (b) some high school; (c) high school graduate; (d) some college; and (e) college graduate. Due to the variation in percentage of participants across each category, for this analysis level of education was collapsed to (a) high school graduate or less and (b) post-high school. As shown in Table 6, the group statistics suggested that participants with less than college education were, on average, more satisfied with aspects of the job than participants with college education.

The mean of participants with post-high school education was higher for pay $(M=6.5)$. The analysis showed that participants with post-high school education were more satisfied with pay than those participants who had at least a high school diploma. The mean scores of CNA with a high school diploma or less were higher than the mean scores of participants with post-high school education for: (a) people you work with (8.6); (b) cooperation among staff (8.2); and (c) amount of support (8.5). The analysis showed that participants with a high school diploma or less were more satisfied with the people with whom they worked with, cooperation they received from others and the amount of support they received to do their job, than those participants who had post-high school education. Mean scores and standard deviations for level of education and job satisfiers are presented in (Table 6).

\begin{tabular}{|c|c|c|c|c|}
\hline Questionnaire Item & & & & \\
\hline \multirow[b]{2}{*}{ How fairly you are paid } & $\begin{array}{l}\text { High School vs College } \\
\text { HS Graduate or less }\end{array}$ & $\begin{array}{c}\mathbf{n} \\
17\end{array}$ & $\begin{array}{l}\text { Mean } \\
4.353\end{array}$ & $\begin{array}{c}\text { SD } \\
2.5481\end{array}$ \\
\hline & Post HS & 18 & 6.5 & 1.7905 \\
\hline \multirow[b]{2}{*}{ People you work with } & HS Graduate or less & 17 & 8.647 & 1.3666 \\
\hline & Post HS & 18 & 6.556 & 2.0065 \\
\hline \multirow{3}{*}{ Cooperation among staff } & HS Graduate or less & 17 & 8.294 & 1.6111 \\
\hline & Post HS & 18 & 6.278 & 2.164 \\
\hline & HS Graduate or less & 17 & 8.588 & 1.6605 \\
\hline Amount of support & Post HS & 18 & 6.111 & 2.4944 \\
\hline
\end{tabular}

A t test was also performed using the same two groups comparing means for each of the following job satisfiers: (a) people you work with ( $\mathrm{t}(33)=3.58, \mathrm{p}<.01)$; (b) cooperation among staff $(\mathrm{t}(33)=.114, \mathrm{p}<.05)$; and (c) amount of support $(\mathrm{t}(33)=3.44$, $\mathrm{p}<.05)$. The mean scores of participants with post-high school education were significantly higher $(M=6.5, S D=1.79)$ than the mean scores of participants with high school education or less (M $=4.3, \mathrm{SD}=2.5$ ). Although the $\mathrm{t}$ tests were performed, there were not enough participants in the individual cells of the subgroups to use the data to conclude any significant findings or generalize the findings to the CNA population. 


\section{Discussion}

The data were primarily used to describe the participants' profile, compare the profile to Castle's 2007 study, describe the findings on the instrument, and recommend replicating the study with a larger sample. However, the findings can be utilized to provide feedback/opportunities to the study sites.AC enterprises recognize that the need for CNAs is likely to increase as the supply of RNs providing direct patient care diminishes in proportion to the number of patients under the Patient Protection and Affordable Care Act. CNAs need to be provided the appropriate information and support to function effectively in the care of the patient and to feel optimally satisfied in their job.

Journal articles were searched in the nursing and business literature. Studies performed in countries outside the United States were examined. Yet, no literature specific to job satisfaction among CNA employed in AC was found. Therefore, expansion of this study to a larger CNA population is recommended in order for AC enterprises to strategically prepare for future CNA provider resources based on evidence for best practices to attract and retain CNA resources.

\section{Limitations}

This study suggests the measures of job satisfaction used by Castle among CNAs in LTC may also have meaning for CNAs in AC [2]. However, the sample size prohibits robust statistical analysis and generalizing study findings beyond the study participants. Sites for this study are located in the southern portion of the United States. The enterprise culture at each site may be uniquely influenced by the culture of their external environments. The site in the Gulf Coast state is rather geographically remote and may exhibit values that differ from urban settings.

Females tend to be the dominate gender in nursing roles at all levels. Nearly all of the participants (97.1\%) in this study as in other CNA studies were female $[2,5]$. Therefore, the findings of this study cannot be generalized to males who work as a CNA. When a majority of the participants represent just one racial group, the findings cannot be generalized to a broader racial group. The overwhelming majority (94.1\%) of CNAs selfidentified as black in this study. Therefore, the findings are not generalizable beyond the black participants.

\section{Implications for Nurse Leaders}

The importance of this study to nursing focuses on maintenance of an adequate CNA workforce. The study is consistent with a national health priority of the Centers for Disease Control National Center for Health Statistics to increase the number of CNAs to meet the expected increase in need for care of an aging population [19].The United States Bureau of Labor Statistics reported the need for skilled CNAs will grow by $20 \%$ by 2020 [21]. Strengthening aspects of the job known to provide satisfaction may help maintain the current CNA workforce. Strengthening the satisfying aspects of the job holds potential for decreasing the overall turnover rate, ultimately decreasing healthcare expenditures related to CNA turnover.

The overall subscale mean scores in this study from lowest to highest were: rewards, work demands, coworkers, workload, training, work content, and quality of care. CNAs were least satisfied with rewards and most satisfied with the quality of care being provided to patients. Dissatisfaction with rewards is not a surprising finding in this study. Pay is acknowledged and recognized to be low. This study showed the importance of the opportunities for advancement. Opportunities seem to exist for the two research sites to improve job satisfaction by creating such rewards as career ladders for CNAs and/or providing education in advanced technical skills in order for CNAs to perform broader patient care activities. Such additional accomplishments could enhance the self-respect of CNAs and garner a higher level of respect.

CNAs rated their chances to discuss their concerns with leadership as low. Each study site seemed to have a critical opportunity to promote collaboration and open dialogue with CNAs. Leadership must take a proactive approach in encouraging CNA to discuss their concerns and suggestions. Concerns need to be handled with the same attention with which other employees' concerns are addressed. Leadership could provide purposeful meetings with CNA; small group or one-on-one to help promote enhanced sharing and communication when appropriate followup is demonstrated.

The findings also support the generalized perception of CNA that they are less important to patient care than other categories of providers in AC. CNA rated their coworkers, teamwork, and cooperation among staff as low. There is an opportunity to improve the effectiveness of collaboration among CNA and other providers who interact with a CNA such as the RN. Ensuring that CNA are expected to actively participate in interdisciplinary patient meetings and rounds could be beneficial. Such a strategy could enhance the plan of care and help the CNA be a part of the team.

Workload was also perceived by the CNA to be an area of dissatisfaction. CNA rated satisfaction with work schedules, amount of time to do the job, and workload as low; workload was the lowest. CNA commonly feel the brunt of patients' living longer with multiple conditions, yet with less ability to provide their own care. It is widely known that CNA may be assigned from 10 to 15 , or more, patients during a shift. Despite the large patient load, CNA are expected to provide multiple components of basic patient care including bathing, ambulating, performing vital signs, feeding, and turning within that shift. The findings suggest that CNA perceive their workload to be impeding their ability to provide the best care possible to the patient. Use of a standard formula for CNA hours per patient day similar to that used for RNs as the basis of staffing matrices for CNA coverage could result in more equitable workloads and lead to improved job satisfaction.

\section{References}

1. Health Careers Center. It's Your Choice; Choose to Care. Available at http://www.mshealthcareers.com/careers/nursingassistant.htm.

2. Castle NG. Assessing job satisfaction of nurse aides in nursing homes: The nursing home nurse aide job satisfaction questionnaire. J Gerontol Nurs. 2007;33(5):41-47.

3. Atchinson JH. Perceived job satisfaction factors of nursing assistants 
employed in Midwest nursing homes. Geriatr Nurs. 1998;19(3):135137.

4. Fitzpatrick PG. Turnover of certified nursing assistants: A major problem for long-term care facilities. Hosp Top. 2002;80(2):21-25. doi: $10.1080 / 00185860209597991$

5. Parsons SK, Simmons WP, Penn K, Furlough M. Determinants of satisfaction and turnover among nursing assistants - The results of a statewide survey. J Gerontol Nurs. 2003;29(3):51-58.

6. Cohen-Mansfield J. Turnover among nursing home staff: A review. Nurs Manage. 1997;28(5):59-62, 64.

7. Chou SC, Boldy DP, Lee AH. Staff satisfaction and its components in residential aged care. Int J Qual Health Care. 2002;14(3):207-217.

8. Moyle W, Skinner J, Rowe G, Gork C. Views of job satisfaction and dissatisfaction in Australian long-term care. J Clin Nurs. 2003;12(2):168176.

9. Syptak J, Marsland D, Ulmer D. Job satisfaction: Putting theory into practice. Family Practice Management. 1999;26-31. http://www.aafp. org/fpm/991000fm/26.html

10. Andrica D. Employee satisfaction. Nursing Economics. 2000;18(6):307.

11. Kaldenberg DO, Regrut BA. Do satisfied patients depend on satisfied employees? Or, do satisfied employees depend on satisfied patients. QRC Advis. 1999;15(7):9-12.

12. Bender K, Donohue S, Heywood J. Job satisfaction and gender segregation. Oxf Econ Pap. 2005;57(3):479-496. doi: 10.1093/oep/gpi015

13. Brown T, Ferrara K, Schley N. The relationship of pregnancy status to job satisfaction: An exploratory analysis. Journal of Business and Psychology. 2002;17(1):63-72. doi:10.1023/A:1016248200163

14. Kirkman B, Shapiro D. The impact of cultural values on job satisfaction and organizational commitment in self-managing work teams: The mediating role of employee resistance. Academy of Management Journal. 2001;44(3):557-569.

15. Koh HC, Boo EHY. The link between organizational ethics and job satisfaction: A study of managers in Singapore. Journal of Business Ethics. 2001;29(4):309-324. doi:10.1023/A:1010741519818
16. Eisenberger R, Stinglhamber F, Vandenberghe C, Sucharski IL, Rhoades L. Perceived supervisor support: contributions to perceived organizational support and employee retention. J Appl Psychol. 2002;87(3):565-573.

17. Smeltzer S, Bare B. Textbook of Medical-Surgical Nursing. Philadelphia: Lippincott Williams \& Wilkins. 10th ed. 2014.

18. Herzberg F. Work and the Nature of Man. New York: The World Publishing Company. 1966.

19. National Center for Health Statistics. National Nursing Home Survey. 2004. Available at http://www.cdc.gov/nchs/about/major/nnhsd/ nnhsdesc.htm.

20. Harrington D, Bean N, Pintello D, Mathews D. Job satisfaction and burnout: Predictors of intentions to leave a job in a military setting. Administration in Social Work. 2001;25(3):1-16.

21. Brady DM. An exploration of nursing assistants' perceptions about job satisfaction. Crit Care Nurs Q. 2016;39(4):371-86. doi: 10.1097/ CNQ.0000000000000131

22. Kalisch B, Lee KH. Staffing and job satisfaction: nurses and nursing assistants. J Nurs Manag. 2014;22(4):465-471. doi: 10.1111/ jonm.12012

23. Liang YW, Hsieh Y, Lin YH, Chen WY. The impact of job stressors on health-related quality of life of nursing assistants in long-term care settings. Geriatr Nurs. 2014;35(2):114-119. doi: 10.1016/j.gerinurse.2013.11.001

24. Meyer D, Raffle $H$, Ware LJ. The first year: employment patterns and job perceptions of nursing assistants in a rural setting. J Nurs Manag. 2014;22(6):769-778. doi: 10.1111/j.1365-2834.2012.01441

25. Prosen M, Piskar F. Job satisfaction of Slovenian hospital nursing workforce. J Nurs Manag. 2015;23(2):242-251. doi: 10.1111/jonm.12121

26. Lerner N, Resnick B, Galik E, Flynn L. Job satisfaction of nursing assistants. J Nurs Adm. 2011;41(11):473-478. doi: 10.1097/ NNA.0b013e3182346e7a

27. Decker FH, Harris-Kojetin LD, Bercovitz A. Intrinsic job satisfaction, overall satisfaction and intention to leave the job among nursing assistants in nursing homes. Gerontologist. 2009;49(5):596-610. doi: 10.1093/geront/gnp051 